\title{
Determinants of Sexual and Reproductive Health Practices of HIV Discordant and Concordant Couples Attending Comprehensive Health Centers in Anambra State, Nigeria
} \author{
Christian Chibuzo Ibeh ${ }^{1,2}$ \\ ${ }^{1}$ Department of Community Medicine, Nnamdi Azikiwe University Teaching Hospital, Nnewi, Nigeria \\ ${ }^{2}$ Department of Community Medicine, Nnamdi Azikiwe University, Nnewi, Nigeria \\ ${ }^{3}$ Department of HIV Care, Nnamdi Azikiwe University Teaching Hospital, Nnewi, Nigeria
}

Adaeze Nnenna Anaekwe ${ }^{1}$, Echendu Dolly Adinma ${ }^{1,2}$, Chinomnso Chinanuekpere Nnebue ${ }^{1,3, \text {, }}$ Chidebe Olisaegboka Anaekwe ${ }^{1}$, Kamtochukwu Maduneme Obi ${ }^{1}$, Achunam Simeom Nwabueze ${ }^{1,2}$,

Email address:

nnebnons@yahoo.com (C. C. Nnebue)

${ }^{*}$ Corresponding author

\section{To cite this article:}

Adaeze Nnenna Anaekwe, Echendu Dolly Adinma, Chinomnso Chinanuekpere Nnebue, Chidebe Olisaegboka Anaekwe, Kamtochukwu Maduneme Obi, Achunam Simeom Nwabueze, Christian Chibuzo Ibeh. Determinants of Sexual and Reproductive Health Practices of HIV Discordant and Concordant Couples Attending Comprehensive Health Centers in Anambra State, Nigeria. Science Journal of Public Health. Vol. 5, No. 1, 2017, pp. 110-116. doi: 10.11648/j.sjph.20170502.18

Received: October 28, 2016; Accepted: December 8, 2016; Published: February 21, 2017

\begin{abstract}
Background: People in discordant partnerships still deserve the right to enjoy sexual relations, and decide whether or not to have children while at the same time taking care not to infect the negative partner and the unborn child. Objective: To identify and compare factors influencing the sexual and reproductive health practices of HIV- concordant and discordant couples attending comprehensive health centers in Anambra state. Materials and methods: This was a cross-sectional comparative study of 289 (148 HIV-concordant and 141 HIV-discordant) couples, selected by a multistage sampling technique. Data were collected by interview using semi-structured questionnaire and analysed with statistical package for social sciences version 22.0. The models that met the criteria for significance, include: a statistically significant chi-square in the omnibus test $(<0.05)$, a non-significant Hosmer Lemeshow test $(>0.05)$, Nagelkerke's R square of at least 0.65 . Results: Presence of support from religious circle and female age $\leq 35$ at couples' HIV diagnosis appear to encourage HIV couples to bear children $(\mathrm{p}=0.007$ and $\mathrm{p}<0.000)$ respectively. Predictor variables that were significantly associated with satisfaction with sexual relationship ( $\mathrm{p}<0.05)$, and contributed to model significance $(\mathrm{p}<0.05)$ consisted of female partner duration on HIV treatment, and safe sex practice method. Conclusions: This study revealed key determinants of the sexual and reproductive health practices of HIV- concordant and discordant couples. Such factors should form the basis for designing novel couple-targeted preventive strategies.
\end{abstract}

Keywords: Sero-concordant, Couples, Sero-discordant, HIV, Sexual and Reproductive Health Practices, Determinants, Anambra State Nigeria

\section{Introduction}

It has been documented that more than eight in every ten women living with HIV and their partners are in their reproductive years [1]. The sexual and reproductive health dilemmas of HIV affected couples after learning of their positive status, include: need for children, starting a family, regulating their fertility [2]. Also HIV infection may affect sexuality because of fear of infecting the sexual partner (s), feelings of guilt and shame aggravated by stigma related to HIV, or emotional or psychological distress, reducing desire for or interest in sexual relations [3].

However, with increasing availability of antiretroviral treatment and improvement in health status, there may be a 
shift in trend, resulting in renewed interest in sexual relations and desire to have children for HIV affected couples [3]. A cross sectional study by Mmbaga et al., reported high fertility intentions [4]. Factors linked to increased fertility desires include: living and having sex with a partner, HIV disclosure [4], absence of a child [3], how fit the mother was or perceived good state of health, high CD4 counts or having an uninfected partner [3], [4]. Biological children were desired by forty percent of participants and lifetime fertility intentions was 2.4 children [5].

The influence of some sociodemographic and other variables on the sexual and reproductive health practices of HIV- discordant couples has also been reported. These variables include: age, age range, gender, duration of marriage, number of children, level of education, income, residence (urbanity and rurality) history of extramarital affairs, alcohol use, viral subtype [6],[7],[8]. A multicenter study by Nostlinger and colleagues, showed that $43 \%$ of the interviewees reported a desire for a child and factors associated with this desire included being younger than 36 (both male and female) and the fact that the couple had no child at all [9]. An exploratory study in Brazil, corroborated that women who had many children who were alive did not want to have more children [10].

Sexual and reproductive health needs and practices of people living with discordance is of paramount importance [11]. This study would help to address the knowledge gaps presently existent in the area of HIV discordance, aid the couples make informed sexual and reproductive health decisions as well as maintain healthy and mutually supportive relations. This study has particularly become timely, especially in this era of health sector reform. It is expected that the findings will guide recommendations and serve as a basis for policy formulation, and putting in place appropriate interventions towards the improvement of the sexual and reproductive health needs and practices of this special group. Therefore we designed this study to identify and compare factors influencing the sexual and reproductive health practices of HIV- concordant and discordant couples attending comprehensive health centers in Anambra state

\section{Materials and Methods}

The study areas were Ukpo in Dunukofia local government area and Neni in Anaocha local government area of Anambra, Nigeria [12]. The study sites were the comprehensive health centers (CHC) in Ukpo and Neni. Ukpo hosts a 30 bed facility which employs different cadre of health workers. This clinic has an average weekly attendance of 60 clients per clinic and at the time of the study had 482 people living with HIV/AIDS accessing care. One hundred and twenty of the couples are in discordant relationships, 140 couples are in a concordant, while. 70 people are single adults and 12 are below 18 years. Clients here are attached to the CHETANWANNE support group. Neni hosts a 35 bed facility with different cadre of health workers. It operates a linkage system with the comprehensive health center Ukpo as both facilities are manned by the same group of doctors on a rotational basis and both clinics run HIV clinic twice weekly. The center has an average weekly attendance of 100 clients for both clinics and presently has 700 people living with HIV accessing care. One hundred and eighty of the couples are in discordant relationships, 180 couples are concordant, 120 adult singles and 40 teenagers. Clients here are attached to the FAVOUR support group.

This was a cross sectional comparative study. The reference population comprised the HIV-discordant and concordant couples in Dunukofia and Anaocha local Government areas of Anambra state, while the target population consisted of the HIV discordant and concordant couples accessing care at the Comprehensive Health Centers Ukpo and Neni Anambra state. Inclusion criteria: The couple had been in a sero-discordant/ concordant sexual relationship for at least six months (A sero-discordant relationship is that in which one of the partners is HIV positive while a sero concordant relationship is one in which both partners are HIV positive); both partners had disclosed his/ her status to the partner; both partners were aged 18 years or older. Exclusion criterion: Those in Sero-discordant / concordant relationships for more than six months who did not give their consent.

The sample size was determined using formula for comparison of 2 proportions [13]:

$$
\begin{gathered}
\mathrm{n}=\frac{\left\{\left\{\mu \sqrt{ }\left[\pi_{1}\left(1-\pi_{1}\right)+\pi_{2}\left(1-\pi_{2}\right)\right]+v \sqrt{ }[\pi(1-\pi)]\right\}^{2}\right.}{\left(\pi_{2}-\pi_{1}\right)^{2}} \\
\Pi=\frac{\pi_{1}+\pi_{2}{ }^{135}}{2}
\end{gathered}
$$

$\mathrm{n}=$ minimum sample size for each group; $\Pi_{2}$ Proportion of sexual and reproductive health needs in discordant couples $=50 \%$ since there is no documented literature comparing the sexual and reproductive health needs of discordant and concordant couples; $\Pi_{1}=$ Proportion of sexual and reproductive health needs in concordant couples $=35 \%$ (anticipating a $15 \%$ difference in sexual and reproductive health needs of discordant and concordant couples. This assumption is made based on conventional practice); $\mu=$ onesided percentage point of the normal distribution corresponding to $100 \%$-the power. $(1-\beta)$ Power $=90 \% . \mu=1.28$; $v=$ percentage of the normal distribution corresponding to the required (two-sided) significance level, significance level $=5 \%, v=1.96$

\section{CALCULATION:}

$$
\frac{\{1.28 \sqrt{ }[0.5(0.5)+0.35(0.65)]+1.96 \sqrt{ }[0.425(1-0.575)]\}^{2}}{(0.15)^{2}}=131 \text {. }
$$

Anticipating a response rate of $90 \%,(\mathrm{f}=\%$ of response $=90 \%$ (0.9)) to compensate for non-response, the study sample size was calculated as (3) $n / f[14]=131 / 0.9=145$ respondents

A multistage sampling technique was used to conduct this 
study. Firstly, from the four comprehensive health centers in Anambra state, two were chosen by simple random sampling using balloting i.e. comprehensive Health centers Ukpo and Neni. Secondly, from the clinics, the sampling frames of the discordant and concordant couples accessing care were obtained. This consisted of the lists of these couples. accessing care at these clinics. At the time of the study, the total number of discordant couples at the two comprehensive centers was 300 while the number of concordant couples was 320. For the discordant couples, simple random sampling using a table of random numbers was employed to select the 145 couples from the sampling frame. To select 145 from 300 , the first 3 digit numbers on the rows in the table were selected. For the numbers that are below 300, they were picked directly but for those above 300 , the numbers were divided by 300 and the remainder was picked. E.g. the first 5 numbers from the table of random numbers are: 034, 977167 125555 . So from the sampling frame the $34^{\text {th }}$ couple, the $77^{\text {th }}$ couple $(977 / 300=3 \mathrm{r} 77)$, the $167^{\text {th }}$ couple were picked. Same was done to obtain the sample size from the concordant couples sampling frame. After the table of random numbers had been used to select the couples to be interviewed, those whose appointment dates fell during the study period were teased out. Those whose appointments fell outside this period were then contacted by phone to inform them of the study and seek their willingness to participate. Appointments were then fixed thereafter when consent had been obtained.

Data was then collected from the selected couples at the clinic, at the support group meetings and at arranged convenient places through telephone calls for those whose appointment days did not fall within the research time frame. Data collection in this study was done using pre-tested, interviewer-administered semi- structured questionnaires. The questionnaire for this study was adapted from that used by the Human Sciences Research Council South Africa and the Global Network of people living with HIV/AIDS [15]. The questionnaire was translated from English to Igbo for those who do not understand the Igbo language. It was then back translated to make sure that it retained its original meaning. Pretesting of the questionnaire was carried out among $10 \mathrm{HIV}$ discordant couples and 10 concordant couples at the Comprehensive Health Centre Umunya, a health facility in Oyi L. G. A. This was done, to check for its reliability and validity. Also determined were the appropriateness of format and wording of the questionnaire as well as time needed to fill them. Thereafter the instruments were reviewed by colleagues, necessary adjustments and corrections were effected before administering the questionnaire to the study participants.

The study was conducted between January and April 2013. Data was collected by 6 trained research assistants along with the researcher. The research assistants were final year medical students. The pre-data collection training was both in English and Igbo and emphasized respect for patient's confidentiality, included basic definition of terms as well. All those who gave consent and whose appointments fell within the study period were interviewed while those whose appointments fell outside the study period, had their interviews fixed with them at a convenient time and place.

To ensure data quality, training of data collection team, field monitoring of data collection was done. Meeting of data collection team at the end of every day to share experiences and submit completed forms, and solving field problems were ensured. At the end of the study, one of the questionnaires could not be traced during analysis hence only 289 questionnaires were analyzed. The data were reviewed and entered into the computer. Data were cleaned by carrying out range as well as by consistency checks. Data were analyzed in respect to the demographic characteristics of the respondents. Age, (like other continuous variables) was also grouped with intervals of five years, from the $<20$ years, to 75 year age range, for both male and female partners. Multivariate analysis using logistic regression was done using predictor variables that were significant in the bivariate analysis (including correlation), with sexual and reproductive health-related variables as outcome variables of interest. Level of significance was set at $5 \%$ or less. The models that met the criteria for significance, include: a statistically significant chisquare in the omnibus test $(<0.05)$, a non-significant Hosmer Lemeshow test ( $>0.05$ ), Nagelkerke's R square of at least 0.65 , and an overall model prediction success of at least $50 \%$. Predictor variables that were not significant in the resultant equations, were removed or replaced with others until a best fit model was obtained, with significant predictors. Satisfaction with sexual relationship, and childbearing after HIV diagnosis, were the sexual and reproductive health outcome variables of interest that satisfied the best fit model. Frequencies of the variables was assessed using univariate analysis, while bivariate analysis, using chi-square and fishers exact, were used to test associations between several variables, comparing concordant and discordant couples with alpha set at 0.05 . Correlation analysis was conducted to determine potential predictor variables of satisfaction with sexual relationship. A multivariate model was then constructed beginning with the potential predictor variables that had the greatest effect on the goodness of fit of the general equation model. Sequential testing of additional predictor variables that were associated with satisfaction with sexual relationship was then carried out in a bivariate analysis into the multivariate model. Only predictor variables that were significantly associated with satisfaction with sexual relationship $(\mathrm{p}<0.05)$, and contributed to model significance $(\mathrm{p}<0.05)$ were selected, while $95 \%$ confidence intervals and adjusted odds ratios are as shown. Descriptive and analytical statistics of the data were carried out using statistical package for social sciences (SPSS) Windows version 22.0 [16].

Ethical approval was obtained from the Nnamdi Azikiwe University Teaching Hospital Ethics Committee Nnewi, Nigeria. A written informed consent was obtained from each participant for the conduct and publication of this research study and assurance of confidentiality given. All authors hereby declare that the study has been performed in accordance with the ethical standards laid down in the 1964 Declaration of Helsinki. 


\section{Results}

Table 1 shows the socio- demographic characteristics of respondents. Data was obtained from 289 respondents, consisting of $148 \mathrm{HIV}$-concordant, and $141 \mathrm{HIV}$-discordant couples. There were more HIV-discordant positive males 83 $(28.6 \%)$ than females $58(20.1 \%)(\mathrm{p}=0.043)$ among both concordant and discordant couples. The mean age (SD) of all, male, and female respondents were 37.8(9.8), 41.1(19.3), and 34.4(9.1) years respectively. In all but one couple, the male partners were older than their female spouses, with 36-40 years being the commonest male age group, for discordant couples, and concordant couples. While 25-30 years was the commonest female age group for both discordant and concordant couples.

Table 2 shows the sexual activity and relationship among concordant and discordant couples. Sexual intercourse was the commonest type of sexual activity 265(99.3\%). Sixtyone $(22.9 \%)$ respondents, do not use condom, with no significant difference seen between concordant and discordant couples $(\chi 2=0.705, \mathrm{p}=0.401)$. About one-fifth $56(19.5 \%)$ of respondents were dissatisfied with sexual relationship, but only $10(7.1 \%)$, had sexual concerns to share. Comparing concordant and discordant couples, there was no difference in satisfaction with sexual relationship $(\chi 2=1.1, p$ $=0.295)$, but more discordant couples had sexual concerns to share $(\chi 2=3.827, \mathrm{p}=0.05)$.

Table 3 shows reproductive intentions among HIV couples More concordant couples $119(41.2 \%)$ had children than their discordant counterparts 107(37.0\%). More discordant couples had also not had children after their HIV diagnosis $76(26.3 \%)$ than the concordant couples 68(23.5\%). Concordant couples who plan to have more children despite their HIV status $77(26.6 \%)$ are more than their discordant counterparts $70(24.2 \%)$. More concordant couples also plan to breastfeed their children $26(9.0 \%)$ than their discordant counterparts.

Table 4 shows determinants of childbearing following couples' HIV diagnosis. Presence of support from religious circle was found to encourage HIV couples to bear children $(\chi 2=7.39, p=0.007)$, but presence of support from family, friends and non-governmental organizations did not significantly influence childbearing. Female age $\leq 35$ following couples' HIV diagnosis also encourage HIV couples to bear children $(\mathrm{p}<0.000)$.

Table 5 shows multiple regression of satisfaction with sexual relationship, with relevant predictors. Predictor variables that were significantly associated with satisfaction with sexual relationship $(\mathrm{p}<0.05)$, and contributed to model significance $(p<0.05)$ consisted of female partner duration on HIV treatment, and safe sex practice method.

Table 1. Sociodemographic characteristics of respondents by relationship status ( $N=578)$.

\begin{tabular}{|c|c|c|c|c|c|c|}
\hline \multirow{2}{*}{\multicolumn{2}{|c|}{ Characteristics }} & \multicolumn{2}{|l|}{ Concordant Couples } & \multicolumn{3}{|l|}{ Discordant Couples } \\
\hline & & $\begin{array}{l}\text { male concordant } n \\
(\%)\end{array}$ & $\begin{array}{l}\text { female concordant } \\
\text { n }(\%)\end{array}$ & $\begin{array}{l}\text { male discordant n } \\
(\%)\end{array}$ & $\begin{array}{l}\text { female discordant } n \\
(\%)\end{array}$ & $\begin{array}{l}\text { Group Total n } \\
(100 \%)\end{array}$ \\
\hline \multirow{8}{*}{$\begin{array}{l}\text { Age } \\
\text { Groups }\end{array}$} & $18-24$ & $0(0.0)$ & $18(85.7)$ & $0(0.0)$ & $3(14.3)$ & $21(100)$ \\
\hline & $25-29$ & $21(13.4)$ & $59(37.6)$ & $17(10.8)$ & $60(38.2)$ & $157(100)$ \\
\hline & $30-34$ & $36(35.6)$ & $28(27.7)$ & $20(19.9)$ & $17(16.8)$ & $101(100)$ \\
\hline & $35-39$ & $36(29.8)$ & $14(11.6)$ & $43(35.5)$ & $28(23.1)$ & $121(100)$ \\
\hline & $40-44$ & $18(34.6)$ & $10(19.2)$ & $16(30.8)$ & $8(15.4)$ & $52(100)$ \\
\hline & $45-49$ & $18(25.4)$ & $15(21.1)$ & $23(32.4)$ & $15(21.1)$ & $71(100)$ \\
\hline & $50-54$ & $12(48.0)$ & $2(8.0)$ & $8(32)$ & $3(12)$ & $25(100)$ \\
\hline & $\geq 55$ & $7(48.3)$ & $2(10.5)$ & $13(47.4)$ & $7(21.0)$ & $30(100)$ \\
\hline \multirow{4}{*}{$\begin{array}{l}\text { Educational } \\
\text { Level }\end{array}$} & Nil & $1(20.0)$ & $0(0.0)$ & $3(60.0)$ & $1(20.0)$ & $5(100)$ \\
\hline & Primary & $50(32.0)$ & $36(23.1)$ & $34(21.8)$ & $36(23.1)$ & $156(100)$ \\
\hline & Secondary & $58(21.4)$ & $83(30.6)$ & $56(20.7)$ & $74(27.3)$ & $271(100)$ \\
\hline & Tertiary & $39(26.7)$ & $29(19.9)$ & $48(32.9)$ & $30(20.5)$ & $146(100)$ \\
\hline \multirow{5}{*}{ Occupation } & Farmer & $12(38.7)$ & $4(12.9)$ & $10(32.3)$ & $5(16.1)$ & $31(100)$ \\
\hline & Civil Serv. & $97(28.2)$ & $81(23.6)$ & $82(23.8)$ & $84(24.4)$ & $344(100)$ \\
\hline & Trader & $28(24.5)$ & $30(26.3)$ & $32(28.1)$ & $24(21.1)$ & $114(100)$ \\
\hline & Others & $11(15.7)$ & $18(25.7)$ & $16(22.9)$ & $25(35.7)$ & $70(100)$ \\
\hline & Unemployed & $0(0.0)$ & $14(77.8)$ & $1(5.5)$ & $3(16.7)$ & $18(100)$ \\
\hline \multirow{2}{*}{$\begin{array}{l}\text { Marriage } \\
\text { Type }\end{array}$} & Monogamy & $132(50.3)$ & & 130 (49.6) & & $262(100)$ \\
\hline & Polygamy & $15(55.6)$ & & $12(44.4)$ & & $27(100)$ \\
\hline \multirow{7}{*}{ Religion } & Pentecostal & $34(47.8)$ & & $37(52.2)$ & & $71(100)$ \\
\hline & Anglican & $39(49.4)$ & & $40(50.6)$ & & 79 (100) \\
\hline & Rom. Cath. & $56(53.8)$ & & $48(46.2)$ & & $104(100)$ \\
\hline & Jeh. Wit & $3(60.0)$ & & $2(40.0)$ & & $5(100)$ \\
\hline & Sabbath & $9(52.9)$ & & $8(47.1)$ & & $17(100)$ \\
\hline & Moslem & $0(0.0)$ & & $1(100)$ & & $1(100)$ \\
\hline & Trad. & $7(63.6)$ & & $4(36.4)$ & & $11(100)$ \\
\hline
\end{tabular}


Table 2. Sexual activity and relationship among concordant and discordant couples.

\begin{tabular}{|c|c|c|c|c|c|c|}
\hline & & Concordant couples n (\%) & Discordant couples n (\%) & Chi-square statistic & degrees of freedom & pvalue \\
\hline sexually active & $\begin{array}{l}\text { yes } \\
\text { no }\end{array}$ & $\begin{array}{l}142(49.3) \\
6(2.1)\end{array}$ & $\begin{array}{l}122(42.4) \\
18(6.3)\end{array}$ & 7.3 & 1 & 0.001 \\
\hline $\begin{array}{l}\text { frequency of sexual } \\
\text { activity (weekly) }\end{array}$ & $\begin{array}{l}\geq 3 \\
<3\end{array}$ & $\begin{array}{l}56(20.9) \\
(31.7)\end{array}$ & $\begin{array}{l}63(23.9) \\
64(23.9)\end{array}$ & 2.65 & 1 & 0.104 \\
\hline condom use & $\begin{array}{l}\text { yes } \\
\text { no }\end{array}$ & $\begin{array}{l}110(41.4) \\
29(10.9)\end{array}$ & $\begin{array}{l}95(35.7) \\
32(12.0)\end{array}$ & 0.705 & 1 & 0.401 \\
\hline $\begin{array}{l}\text { one or both partners has } \\
\text { arousal difficulty }\end{array}$ & $\begin{array}{l}\text { yes } \\
\text { no }\end{array}$ & $\begin{array}{l}20(7.5) \\
120(44.9)\end{array}$ & $\begin{array}{l}8(3.0) \\
119(44.6)\end{array}$ & 4.525 & 1 & 0.033 \\
\hline $\begin{array}{l}\text { satisfaction with sexual } \\
\text { relationship }\end{array}$ & $\begin{array}{l}\text { yes } \\
\text { no }\end{array}$ & $\begin{array}{l}114(39.7) \\
32(11.1)\end{array}$ & $\begin{array}{l}117(40.8) \\
24(8.4)\end{array}$ & 1.1 & 1 & 0.295 \\
\hline $\begin{array}{l}\text { have sexual concerns to } \\
\text { share }\end{array}$ & $\begin{array}{l}\text { yes } \\
\text { no }\end{array}$ & $\begin{array}{l}6(2.1) \\
137(48.9)\end{array}$ & $\begin{array}{l}4(5.0) \\
123(43.9)\end{array}$ & 3.827 & 1 & 0.05 \\
\hline
\end{tabular}

Table 3. Reproductive intentions among HIV couples.

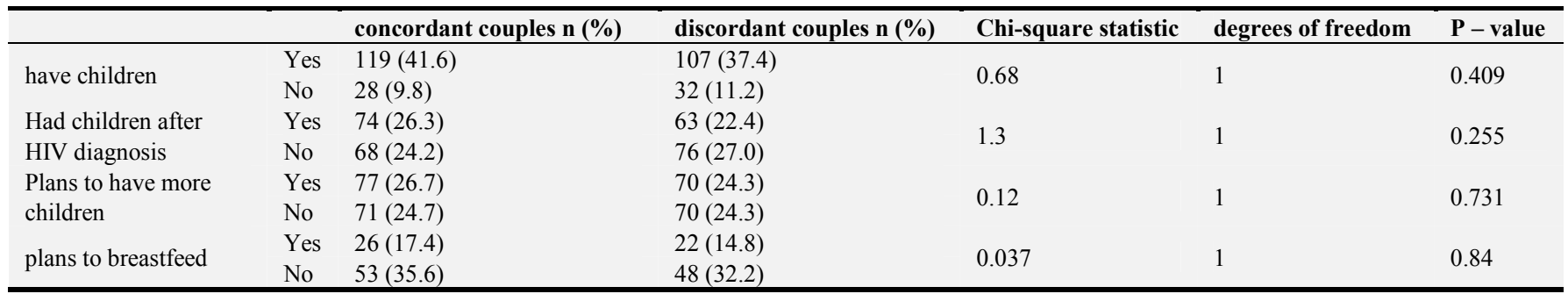

Table 4. Determinants of childbearing following couples' HIV diagnosis.

\begin{tabular}{|c|c|c|c|c|c|}
\hline \multirow{2}{*}{ Variable } & \multicolumn{3}{|c|}{ Childbearing post-diagnosis } & \multirow{2}{*}{ Chi-square statistic } & \multirow{2}{*}{ p-value } \\
\hline & & concordant n (\%) & discordant n (\%) & & \\
\hline \multirow{2}{*}{ female age $\leq 35$} & Yes & $107(38.1)$ & $71(25.3)$ & \multirow{2}{*}{25.07} & \multirow{2}{*}{$<0.00$} \\
\hline & No & $30(10.7)$ & $73(26.0)$ & & \\
\hline \multirow{2}{*}{ Presence of family support } & Yes & $68(24.4)$ & $77(27.6)$ & \multirow{2}{*}{0.27} & \multirow{2}{*}{0.6} \\
\hline & No & $67(24.0)$ & $67(24.0)$ & & \\
\hline \multirow{2}{*}{ Presence of support from friends } & Yes & $16(5.7)$ & $23(8.2)$ & \multirow{2}{*}{0.98} & \multirow{2}{*}{0.32} \\
\hline & No & $119(42.7)$ & $121(43.4)$ & & \\
\hline \multirow{2}{*}{ Presence of support from religious circle } & Yes & $29(10.4)$ & $14(5.0)$ & \multirow{2}{*}{7.39} & \multirow{2}{*}{0.007} \\
\hline & No & $106(38.0)$ & $130(46.6)$ & & \\
\hline \multirow{2}{*}{ Presence of NGO support } & Yes & $71(25.4)$ & $77(27.6)$ & \multirow{2}{*}{0.022} & \multirow{2}{*}{0.883} \\
\hline & No & $64(22.9)$ & $67(24.0)$ & & \\
\hline \multirow{2}{*}{ Experience of conflict due to HIV status } & Yes & $114(41.0)$ & $123(44.2)$ & \multirow{2}{*}{0.14} & \multirow{2}{*}{0.71} \\
\hline & No & $21(7.6)$ & $20(7.2)$ & & \\
\hline
\end{tabular}

Table 5. Multiple regression of satisfaction with sexual relationship, with relevant predictors.

\begin{tabular}{|c|c|c|c|c|c|c|c|c|}
\hline \multirow[b]{2}{*}{ Model } & \multirow[b]{2}{*}{ predictor variables } & \multirow{2}{*}{$\begin{array}{l}\text { Odds Ratio }(95 \% \\
\text { CI) }\end{array}$} & \multirow{2}{*}{$\begin{array}{l}\text { Adjusted } \\
\text { Odds Ratio }\end{array}$} & \multirow[b]{2}{*}{ p-value } & \multirow[b]{2}{*}{ Intercept } & \multicolumn{3}{|c|}{ Model Properties } \\
\hline & & & & & & $\mathbf{N}$ square & HL test & $\begin{array}{l}\text { overall model } \\
\text { significance }\end{array}$ \\
\hline \multirow{2}{*}{1} & female duration on HIV treatment & $-1.6(-1.92,1.04)$ & -1.44 & 0.025 & \multirow{2}{*}{0.517} & \multirow{2}{*}{0.61} & \multirow{2}{*}{0.214} & \multirow{2}{*}{ Good } \\
\hline & safe sex practice method & $0.11(0.04,0.23)$ & 0.16 & 0.00 & & & & \\
\hline \multirow{5}{*}{2} & female duration on HIV treatment & $1.98(1.18,2.21)$ & 1.51 & 0.02 & \multirow{5}{*}{-0.016} & \multirow{5}{*}{0.32} & \multirow{5}{*}{0.63} & \multirow{5}{*}{ Poor } \\
\hline & female age group at 36 years & $6.87(5.31,7.49)$ & 7.04 & 0.01 & & & & \\
\hline & Sexually active couple & $0.33(0.28,0.52)$ & 0.31 & 0.186 & & & & \\
\hline & safe sex practice method & $0.04(0.03,0.06)$ & 0.05 & 0.02 & & & & \\
\hline & female feeling of anger & $10.9(8.31,12.42)$ & 9.43 & 0.027 & & & & \\
\hline
\end{tabular}

$*=$ Negelkerke R square; **= Hosmer Lemeshow test; ***= considered poor due to low $\mathrm{N} \mathrm{R}$ square

\section{Discussion}

This comparative study determined the factors affecting the sexual and reproductive health practices of HIV discordant and concordant couples in two Comprehensive health centers in Anambra state. A high response rate $(99.2 \%)$ was obtained from this study and was similar to the rates obtained in studies in Ethiopia [17] and in Zambia.18].

Comparing concordant and discordant couples, our study found no difference in satisfaction with sexual relationship, but more discordant couples had sexual concerns to share compared with concordant couples. These concerns are related to the factors which have affected intimacy in these 
couples which include: difficulty in initiating sex, problems with arousal, decrease in libido etc. This finding is consistent with findings in other studies in which HIV discordant couples highlighted their unique challenge and concerns, which included intimacy issues, support and reproductive decisions [19], [20]. The low number expressing these concerns might be related to the society in which the study was carried out and the prevailing sociocultural dynamics with regards to sexual and reproductive health issues. In this setting, sexual matters are seen as issues of high privacy and should be kept within the couple, no matter the situation. This is corroborated by the findings of a nested intervention by King et al., in Uganda, which showed that cultural complexities play a major role in influencing the behavior of discordant couples [21].

Our study revealed that presence of support from family, friends and non-governmental organizations did not significantly influence childbearing, while presence of support from religious circle appears to encourage HIV couples to bear children. This helped the clients to feel that a Supreme being was in charge of everything and could help them live a fulfilled life despite their HIV status. This is in keeping with findings from another study which affirmed religious leaders as partners in fostering positive reproductive health and family planning behavior [22].

The index study revealed that female age $\leq 35$ following couples' HIV diagnosis appear to encourage HIV couples to bear children. This finding agrees with that of a multicenter study in Europe, which showed that $43 \%$ of those interviewed reported a desire for a child and factors associated with this desire included being younger than 36years of age [9]. This finding is also consistent with findings of several studies [6], [7], [8].

From our study, the predictor variables that were significantly associated with satisfaction with sexual relationship and contributed to model significance were female partner duration on HIV treatment, and safe sex practice method. Jones et al., had reported that those whose partners participated intensively in programs on sexual risk behavior reduction among HIV-positive Zambian women, showed more positive condom attitudes and safer sex practices than those of low participation [23].

\section{Limitations}

This study should be interpreted in light of its limitations. Firstly, the cross-sectional design implies that only association, but not causal inferences can be made. Secondly, self-reported assessments of sexual issues through questionnaires are prone to a number of biases that could affect the validity and reliability of the results. Also, HIV/AIDS and sexual issues are very sensitive and could limit free expression of respondents. Assurance of confidentiality of the respondents, the training of research assistants to be painstaking in answering possible questions raised by respondents during data collection, as well as the simplicity and direct nature of the questions in the questionnaires minimised these effects.

\section{Conclusions}

The major factors affecting the sexual and reproductive health needs particularly childbearing issues of both concordant and discordant couples were support from their religious circle, female age $\leq 35$ following couples' HIV diagnosis, female partner duration on HIV treatment, and safe sex practice method. Based on the findings, we recommend that the role of religious organizations in encouraging childbearing among concordant and discordant couples should be monitored and checked against present guidelines of ensuring the safety of the mother and prevention of mother to child transmission. This should of course be provided in a supportive and non-discriminatory environment.

\section{Acknowledgements}

This work was part of a dissertation submitted to the West African College of Physicians in part fulfilment of the requirements for the award of the Fellowship of the College in Community Health.

\section{References}

[1] Shan D, Ge Z, Ming S, Wang L, Sante M, He W et al. Quality of life and related factors among HIV-positive spouses from serdiscordant couples under antiretroviral therapy in Henan Province China. PLoS One. 2011; 6 (6): e21839.

[2] Rispel LC, Cloete A, Metcalf CA, Moody K, Caswell G. It [HIV] is part of the relationship: exploring communication among HIV dis-cordant couples in South Africa and Tanzania. Culture, Health and Sexuality. 14 (3), 257-268

[3] Shuaib FM, Ehiri JE, Jolly P, Zhang O, Emusu D, Ngu J et al. Sexual violence and associated factors among women in HIV discordant and concordant relationships in Uganda. Int $J$ Adolescent Med Health. 2012; 24 (2): 125-33.

[4] Mmbaga EJ, Leyna GH, Ezekiel MJ, Kakoko DC. Fertility desire and intention of people living with HIV/AIDS in Tanzania: a call for restructuring care and treatment services. BMC Public Health. 2013; 13; 86.

[5] Ikechebelu JI. Mbamara SU. Sexual practices of people living with HIV in South eastern Nigeria. Nigerian Journal of Clinical Practice. 2009; 12 (4): 416-420.

[6] Landolt K. Ramautarsing R. Factors associated with the use of irreversible contraception and continuous use of reversible contraception in a cohort of HIV- positive women. Contraception. 2013; 88 (1): 67-73.

[7] Maharaj P, Oleland J. Risk perception and condom use among married or cohabiting couples in Kwazulu-Natal, South Africa. International. Family Plannning Perspectives. 2005; 31 (1): 24-29.

[8] Akani C, Erhabor O, Opurum H, Ejele O, Nwauche C. HIV sero- discordance among Nigerian couples: challenges and controversies. Nigerian Medical Practiioner. 2005; $48: 3$. 
[9] Nöstlinger C, Desjardins F, Dec J, Platteau T, Hasker E; Eurosupport V Study Group. 2013. Child desire in women and men living with HIV attending HIV outpatient clinics: evidence from a European multicenter study. Eur J. contrcept Report Health Care. 2013; 18 (4): 251-263.

[10] Santos N, Buchalla M. Reproduction and sexuality in HIVpositive women, Brazil. Rev. Saude Publica 2002; 36 (4 suppL) 12-23.

[11] Bell E, Mthembu PO' Sullivan S. Sexual and reproductive health services and HIV testing: perspectives and experiences of women and men living with HIV and AIDS. Reproductive Health Matters. 2007; 15 (29 Supplement): 113-135.

[12] Dunukofia.

Available@ http://en.wikipaedia.org/wiki/Dunukofia.[Last accessed 2013 25].

[13] Kirkwood B. Essentials of medical statistics. Blackwell Scientific Publications. $2^{\text {nd }}$ Edition 2001. p. 190.

[14] Araoye MO. Research methodology with statistics for health and social sciences. Nathadex Publications, saw-mill, Ilorin 2nd ed.2008: p 115-122.

[15] Questionnaire modified from that of Human Sciences Research Council South Africa and Global Network of people living with AIDS. Available@www. stigmaindex. Org /.../ Summary-Booklet-on-Stigma-Index-Survey\%20South\%20A.. [Last accessed on 2014 Jan 14].

[16] Statistical Package for Social Sciences (IBM SPSS) 22.0 version. Armonk NY: IBM United States. IBM Corp. 2013.
[17] Tadesse M. Assessment of HIV discordance and associated risk factors among couples receiving HIV test in Dilla, Ethiopia. BMC Research Notes. 20147: 893 DOI: 10.1186/1756-0500-7-893

[18] Nozaki I, Dube C, Kazuihiro K, Yamada N, James B. Social factors affecting ART adherence in rural settings in Zambia. AIDS Care. 2011; 23 (7): 831-839.

[19] Bunnell RE, Nassozi J, Marum E, Mubangizi J, Malamba S, Dillon B, et al. Living with discordance: Knowledge, challenges, and prevention strategies of HIV-discordant couples in Uganda. AIDS Care.2005; 17 (8): 999-1012.

[20] Santelli J S, Kouzis AC. Stage of behavior change for condom use: the influence of partner type, relationship and pregnancy factors. Family Planning Perspectives. 2006; 28 (3): 101-107.

[21] King R, Wamai N. Maybe his blood is still strong: a qualitative study among HIV sero-discordant couples on ART in rural Uganda. BMC Public Health. 2012; 12: 801.

[22] USAID - Muslim Religious leaders as partners in fostering positive reproduce Health family planning behaviours: A best practice. www.pathfinder.org/publications-tools/pds/muslim religious leaders. [Last accessed on 2013 June 23].

[23] Jones D L, Ross D. Influence of partner participation on sexual risk behavior reduction among HIV-positive Zambian women. Journal of Urban Health.2005; 82 (3 Suppl 4): iv92100 . 